\title{
Silvia Cantara
}

\author{
Section of Endocrinology and Metabolism, Department of Internal Medicine, \\ Endocrinology \& Metabolism and Biochemistry, University of Siena, Italy.
}

\begin{abstract}
Fine Needle Aspiration Cytology (FNAC) is the "gold standard" for the differential diagnosis of thyroid nodules, but has the limitation of inadequate sampling or indeterminate lesions. Our Unit of Endocrinology was involved in a pilot study aimed to verify whether search of thyroid cancer-associated proto-oncogene mutations in cytological samples may improve the diagnostic accuracy of FNAC. Our results demonstrated that the presence of mutations at cytology was associated with cancer $91.1 \%$ of the times and with follicular adenoma $8.9 \%$ of the times. BRAF or RET/PTC mutations were always associated with cancer, while RAS mutations were mainly associated with cancer (74\%) but also with follicular adenoma $(26 \%)$. The diagnostic performance of molecular analysis was superior to that of traditional cytology, with better sensitivity and specificity, and the combination of the two techniques further contributed to improve the total. At the moment, we have introduced the search for the most common mutations (BRAF, 3 RAS isoforms and RET/PTC rearrangements) in the clinical practice especially in those FNAC which resulted indeterminate at the first cytological analysis. Keywords: Thyroid cancer, Fine needle aspiration cytology, molecular analysis
\end{abstract}

Fine needle aspiration cytology (FNAC) is the "gold standard" for the differential diagnosis of thyroid nodules $(1,2)$. In general, in expert hands, it is associated with good specificity and acceptable sensitivity (3). However, this procedure have some limitations related to inadequate sampling or to the difficulty to discriminate follicular lesions. Therefore, a significant proportion of patients who do not have malignant lesions are submitted to unnecessary thyroidectomy.

The discovery of genetic alterations specific for differentiated thyroid cancer may provide molecular markers to be searched for in the material obtained by FNA, thus increasing the diagnostic accuracy of traditional cytology. Search of BRAF mutations in cytological material has been reported with encouraging results (410). However, BRAF mutation account for no more than $30-40 \%$ of papillary thyroid carcinomas and cannot cover the entire spectrum of thyroid malignancies. The ideal tool should be to search for all, or at least the most frequent, oncogenes involved in thyroid tumorigenesis. This approach has been recently implemented in some studies (11-15) which demonstrated that screening thyroid nodules for RET, BRAF and RAS mutations allowed to improve the diagnostic accuracy of traditional cytology.

Our Unit of Endocrinology was involved in pilot studies aimed to evaluate the diagnostic utility of screening cytological samples for a complete panel of mutations, including those associated with BRAF, RET, RAS, TRK, and PPRY proto-oncogenes. From the methodological point of view, our results conducted on 225 FNA and the corresponding surgical samples indicate that the search of proto-oncogene mutations in cytological samples is feasible and informative, although some technical aspect remains to be improved. Indeed, in nearly half of our cytological samples, we could not assess RET/PTC rearrangements, due to low quantity of material or bad quality of RNA. This problem can be overcome by increasing the number of needle passes. Nevertheless, the comparison between molecular analysis in cytological samples and tissue samples (where the above limitation was not present) showed that the RNA issue only marginally affected the performance of the method. As a matter of fact, the overall concordance was satisfactory $(88.2 \%)$ and the discrepant results in favour of tissue samples $(11.8 \%)$ were mainly dependent from RET/PTC analysis (5 cases) but not from RAS and BRAF analysis ( 2 cases each).

In our hands, molecular biology on cytological samples correctly identified $78.2 \%$ of the thyroid cancer diagnosed at final histology as opposed to $58.9 \%$ identified by traditional cytology. In other words, 15 out of 78 thyroid carcinomas were missed by cytology and were detected by molecular biology.

As in other series, BRAF mutations (restricted to the V600E residue) (4-10) or RET/PTC rearrangements (11-15) were associated with thyroid cancer in $100 \%$ of the cases and were never found in benign nodules or follicular adenomas. In other reports, the search of RET/PTC rearrangements has been restricted to RET/PTC- 1 and $3(11,14,15)$ and in other studies to RET/PTC-1-2-3 (12,13,16). In our series, RET/PTC mutations were mainly represented by RET/PTC- 1 and 3, 
but also one RET/PTCX $(9.0 \%)$ was found, indicating the need of searching for any RET/PTC rearrangement. Our study included also the analysis of RAS mutations that were associated with thyroid cancer in $74 \%$ of the cases. The remaining RAS mutations (26\%) were found in follicular adenomas. This figure is very close to that of Nikiforov et al. (15) who found that among 8 RAS positive samples, $7(87.5 \%)$ were associated with thyroid cancer and one with follicular adenoma. The issue of RAS mutations deserves special discussion. Theoretically, when the RAS mutation is found in follicular adenoma, it should be considered as a false positive result. However, a follicular adenoma harbouring a RAS mutation might be viewed as a pre-malignant lesion (17), which deserves surgical treatment rather than follow-up. In this view, the RAS mutation found in follicular adenoma might be regarded as true positive (17). In the analysis of diagnostic performance, we considered both possibilities and the result is that the overall PPV increases from $91 \%$ to $100 \%$ when the RAS mutation is computed as false positive or true positive, respectively.

As well known, a FNAC indicative of thyroid cancer is very rarely falsely positive (3). In this category molecular biology does not add diagnostic information, although the knowledge of a mutation associated with worst outcome (BRAF) may influence the surgical strategy (9). The great advantage of molecular analysis is found in the other cytological categories: indeterminate, benign and inadequate lesions. In these groups (181 FNACs), we observed 32 thyroid cancers (false negative results). Molecular biology was able to detect 24 of them $(75 \%): 6 / 9$ in the benign group, $6 / 7$ in the indeterminate group and $12 / 16$ in the inadequate group. Thus, we concluded that whenever a mutation is found in these cytological categories we recommend total thyroidectomy. On the contrary, when no mutation is found the therapeutic strategy should be dictated by the clinicl picture and the results of FNAC: follow-up for benign cytologies, repeat FNAC for inadequate samples and lobectomy for indeterminate lesions.

After these pilot studies, we introduced the search for the most common mutations (BRAF, 3 RAS isoforms and RET/PTC rearrangements) in the clinical practice especially in those FNAC which resulted indeterminate at the first cytological analysis. To date we have analyzed 34 inadequate samples and 75 indeterminate samples finding 1 and 4 mutations respectively leading to an overall percentage of $3.5 \%$ of cancer cases which were not correctly diagnosed by the cytological exam.

\section{REFERENCES}

1. Cooper DS, Doherty GM, Haugen BR, Kloos RT, Lee SL, Mandel SJ, Mazzaferri EL, McIver B, Sherman SI, Tuttle RM 2006 American Thyroid Association Guidelines Taskforce Management guidelines for patients with thyroid nodules and differentiated thyroid cancer. Thyroid 16:109142 .

2. Pacini F, Schlumberger $M$, Dralle H, Elisei R, Smit JWA, Wiersinga $W$ and the European Thyroid Cancer Taskforce 2006 European consensus for the management of patients with differentiated thyroid carcinoma of the follicular epithelium. Eur J Endocrinol, 154:1-18.

3. Baloch ZW, Cias ES, Clark DP, Layfield LJ, Ljung BM, Pitman MB, Abati A 2008. The National Cancer Institute Thyroid Fine Needle Adspiration state if the science conference: a summation. Cyto J 5:6.

4. Cohen Y, Rosenbaum E, Clark DP, Zeiger MA, Umbricht CB, Tufano $R P$, Sidransky D, Westra W 2004 Mutational analysis of BRAF in Fine needle aspiration biopsies of the thyroid: a potential application for the preoperative assessment of thyroid nodules. Clin Cancer Res 10:2761-65. 5. Chung K, Yang SK, Lee GK, Kim EY, Kwon S, Lee SH, Park DJ, Lee HS, Cho BY, Lee ES, Kim SW 2006 Detection of BRAF (V600E) mutation on fine needle aspiration specimens of thyroid nodule refines cyto-pathology diagnosis, especially in BRAF (V600E) mutation-prevalent area. Clin Endocrinol 65:660-666.

6. Sapio MR, Guerra A, Posca D, Limone PP, Deandrea M, Motta M, Troncone G, Caleo A, Vallefuoco P, Rossi G, Fenzi G, Vitale M 2007 Combined analysis of galectin-3 and BRAFV600E improves the accuracy of fine-needle aspiration biopsy with cytological findings suspicious for papillary thyroid carcinoma. Endocr Relat Cancer 14:1089-1097.

7. Moon HJ, Kwak JY, Kim EY, Choi JR, Hong SWH, Kim MJ, Son EJ 2009 The role of BRAF (V600E) mutation and ultrasonography for the surgical Management of thyroid nodule suspicious for papillary thyroid carcinoma on cytology. Ann Surg Oncol [Epub ahead of print].

8. Jo YS, Huang S, Kim YJ, Lee IS, Kim SS, Kim JR, Oh T, Moon Y, An S, Ro HK, Kim JM, Shong M 2009 Diagnostic value of pyrosequencing for the BRAF V600E mutation in ultrasound-guided fine-needle aspiration biopsy samples of thyroid incidentalomas. Clin Endocrinol (Oxf) 70:139-44.

9. Xing M, Tufano RP, Tufaro AP, Basaria S, Ewertz M, Rosenbaum E, Byrne PJ, Wang J, Sidransky D, Ladenson PW 2004 Detection of BRAF mutation on fine needle aspiration biopsy specimens: a new diagnostic tool for papillary thyroid cancer. J Clin Endocrinol Metab 89:2867-2872. 10. Marchetti I, Lessi F, Mazzanti CM, Bertacca G, Elisei R, Di Coscio G, Pinchera A, Bevilacqua G 2009 A Morpho-molecular diagnosis of papillary thyroid carcinoma: BRAF V600E detection an important tool in preoperative evaluation of fine needle aspirates. Thyroid 19:837-42.

11. Salvatore G, Giannini R, Faviana P, Caleo A, Migliaccio I, Fagin JA, Nikiforov YE, Troncone G, Palombini L, Basolo F, Santoro M 2004 Analysis of BRAF point mutation and RET/PTC rearrangement refines the fine-needle aspiration diagnosis of papillary thyroid carcinoma. $J$ Clin Endocrinol Metab 89:5175-5180.

12. Sapio MR, Posca D, Raggioli A, Guerra A, Marotta V, Deandrea $M$, Motta M, Limone PP, Troncone G, Caleo A, Rossi G, Fenzi G, Vitale M 2007 Detection of RET/PTC, TRK and BRAF mutations in preoperative diagnosis of thyroid nodules with indeterminate cytological findings. Clin Endocrinol (Oxf). 66:678-83.

13. Domingues R, Mendoca E, Sobrinho L, Bugalho J 2005 Searching for RET/PTC rearrangement and BRAF V599E mutation in thyroid aspirates might contribute to establish a preoperative diagnosis of papillary thyroid carcinoma. Cytopathology 16:27-31.

14. Pizzolanti G, Russo L, Richiusa P, Bronte V, Nuara RB, Rodolico V, Amato MC, Smeraldi L, Sisto PS, Nucera M, Bommarito A, Citarrella $R$, Lo Coco R, Cabibi D, Lo Coco A, Frasca F, Gulotta G, Latteri MA, Modica G, Galluzzo A, Giordano C 2007 Fine-needle aspiration molecular analysis for the diagnosis of papillary thyroid carcinoma through BRAF V600E mutation and RET/PTC rearrangement. Thyroid 17:1109-1115. 15. Nikiforov YE, Steward DL, Robinson-Smith TM, Haugen BR, Klopper JP, Zhu Z, Fagin JA, Falciglia M, Weber K, Nikiforova MN 2009 Molecular testing for mutations in improving the fine-needle aspiration diagnosis of thyroid nodules 94:2092-8.

16. Cheung CC, Carydis B, Ezzat S, Bedard YC, Asa SL 2001 Analysis of ret/PTC gene rearrangements refines the fine needle aspiration diagnosis of thyroid cancer. J Clin Endocrinol Metab 86:2187-2190.

17. Nikiforova MN, Lynch RA, Biddinger PW, Alexander EK, Dorn GW 2nd, Tallini G, Kroll TG, Nikiforov YE. 2003 RAS point mutations and PAX8-PPAR gamma rearrangement in thyroid tumors: evidence for distinct molecular pathways in thyroid follicular carcinoma. J Clin Endocrinol Metab. 2003 88:2318-26. 